\title{
Angiopoietin-like Protein 4 and the level of Free Fatty Acids in Human Blood Plasma: Is there a link?
}

\section{Faisal H H Ali ${ }^{1,2 *}$ and Yazan Ranneh ${ }^{1}$}

${ }^{1}$ Department of Nutrition and Dietetics, Faculty of medicine and health sciences, Nutrigenomics Programme, Universiti Putra Malaysia, 43400 UPM Serdang, Selangor, Malaysia

${ }^{2}$ Metabolism and genomics group, Division of Human Nutrition, Wageningen University, Bomenweg 2, 6703 HD Wageningen, The Netherlands

\begin{abstract}
Background: Angiopoietin-like protein 4 (Angpt|4) is a new circulating protein of the Angiopoietin-like family, predominantly expressed in adipose tissue and liver. A link between Angptl4 and the levels of free fatty acids in human blood plasma remains unclear. Therefore, we hypothesized that any alteration in the concentration of plasma Angptl4 may be mediated by changes in plasma free fatty acid levels in healthy individuals.
\end{abstract}

Methods: To examine the effect of plasma free fatty acid levels on Angpt/4 concentrations in humans, ELISA method was developed and used for the quantitative determination of human Angptl4 in plasma samples with known free fatty acid concentrations.

Results: It was clearly observed that there were significant $(P$. value $<0.01)$ positive correlation between plasma Angptl4 concentrations and plasma levels of free fatty acid $(0.905 \leq r \leq 1.00)$ and the standard curve using the human recombinant Angpt 4 fragments yielded a consistent $r^{2}$ value $>0.993$. Raising plasma fatty acids resulted in an increase in the levels of Angpt|4. While, lowering plasma fatty acids resulted in a decrease in the levels of Angpt/4.

Conclusion: The results of this study indicate that changes in plasma free fatty acid levels are associated with alterations in the concentrations of Angpt|4.

Keywords: Angptl4; FFAs; Human blood plasma; ELISA; Dyslipidemia

\section{Introduction}

Dyslipidemia (abnormality of lipid metabolism) is the major risk factor of metabolic syndrome, cardiovascular disease and type 2 diabetes mellitus [1]. It is characterized by elevated level of plasma triglyceride (TG), increased levels of low-density lipoprotein (LDL), and decreased high-density lipoprotein cholesterol (HDL-C). Furthermore, high plasma TG also called hypertriglyceridemia is the major health problems in the world and affecting about 47 million (24\%) of the U.S adult population [2]. So, effective therapeutic approaches to combat it are currently of interest. More recently, a family of proteins structurally similar to the angiogenic regulating factors angiopoietins has been identified and designated "angiopoietin-like proteins" (Angptls) or angiopoietin-related proteins. Several studies in mice show that Angptls family proteins play an important role in the regulation of plasma lipid, and energy metabolism independently of angiogenic effects [3-8].

Angiopoietin-like 4 (Angptl4) is one of the recently secreted Angptls with a predicted molecular weight of approximately $50 \mathrm{kDa}$ that belongs to the angiopoietin family and is involved in angiogenesis and metabolism regulation [9-13]. Angptl4 was discovered by three different groups at the same year by different names, e.g., PGAR [peroxisome proliferator-activated receptor $\gamma$ (PPAR $\gamma$ ) angiopoietin related], FIAF (fasting-induced adipose factor), or HFARP (hepatic fibrinogen/ angiopoietin-related protein) [14-16]. A number of studies reported that Angptl4 protein can be detected in various mouse and human tissues where it is produced as well as in mouse and human blood plasma [15,17]. In addition, the metabolic role of Angptl4 has been extensively studied in a variety of tissues particularly in mice.

Indeed, it has been reported that Angptl4 plays an important role in the regulation of lipoprotein metabolism, adiposity both in vivo and in vitro. Furthermore, subsequent studies in mice have been shown that Angptl4 potently elevates triglycerides-rich lipoprotein in plasma [10,17-23]. In pathophysiology, elevated plasma fatty acids concentrations are associated with metabolic syndrome and its accompanying disorders such as diabetes and obesity [1,2]. In normal state, high fatty acid concentrations in plasma are highly connected with prolonged fasting and exercise [24]. Non etserified fatty acids (NEFAs) or free fatty acids (FFAs) are derived from either lipolysis of adipose tissue TG or chylomicrons of dietary fat [24-26].

Currently, it has become increasingly clear from the collective data using experimental animals that Angptl4 plays an important role in the regulation of free fatty acids concentration in blood plasma via stimulating adipose tissue lipolysis $[4,5,17]$. Importantly, functional tests indicated that Angptl4 Prevents the clearance of triglycerides from the TG-rich lipoproteins VLDL and chylomicrons, most likely by inhibiting lipoprotein lipase, a key regulatory enzyme in fatty acid metabolism that is synthesized mainly in muscle and adipose tissue. Decreased LPL activity leads to higher plasma TG levels and thereby, increases of TG lipolysis in adipose tissue into free fatty acids and glycerol [10-12]. Rising in plasma FFAs in transgenic mice can be explained by adipose tissue lipolysis and thereby prevent fat storage and stimulate the mobilization of adipose TGs. For this reason Angptl4 has been considered as a new modulator of plasma FFAs level in mice $[5,8]$.

However, in human, the physiological and nutritional role of the later regulation remains unclear. Interestingly, the genetic evidence has

*Corresponding author: Faisal $\mathrm{H} \mathrm{H}$ Ali, Metabolism and genomics group Division of Human Nutrition, Wageningen University, Bomenweg 2, $6703 \mathrm{HD}$ Wageningen, The Netherlands, Tel: +60389472435, Fax: +60389426769 E-mail: sshrmany@yahoo.co.uk

Received September 05, 2013; Accepted September 27, 2013; Published September 30, 2013

Citation: Ali FHH, Ranneh Y (2013) Angiopoietin-like Protein 4 and the level of Free Fatty Acids in Human Blood Plasma: Is there a link? Med chem 3: 276-281. doi:10.4172/2161-0444.1000151

Copyright: $\odot 2013$ Ali FHH, et al. This is an open-access article distributed under the terms of the Creative Commons Attribution License, which permits unrestricted use, distribution, and reproduction in any medium, provided the original author and source are credited. 
been shown that knockout of the gene for either Angptl3 or Angptl4 in mice leads to activation of the lipoprotein lipase (LPL) and decreased level of triglycerides in plasma. Whereas, transgenic over expression of Angptls leads to decreased LPL activity and thereby, increased plasma triglycerides and adipose tissue lipolysis [11,12]. In mice, Angptl4 expression are increased by fasting, hypoxia and reduced by high-fat feeding [24]. In resent research, it has become evident that Angptl4 over expression significantly increased plasma levels of the free fatty acid in Angptl4 transgenic-mice especially in the fasted state by stimulation adipose tissue lipolysis.

But so far very little is known about the relationship between plasma FFAs level and Angptl4 concentration in humans. Therefore, this study aimed to investigate whether changes in the plasma free fatty acid concentrations under a variety of physiological stimuli, influence the plasma levels of Angptl4 in healthy individuals and also to determine the variations in the concentration of Angptl4 in human blood by using ELISA technique for the quantitative determination of this protein in plasma. This might provide better insight into the metabolic function of Angptl4 in human blood which could be classified as a new class of lipid metabolism modulator and an independent marker for dyslipidemia.

\section{Materials and Methods}

\section{Materials}

The biotinylated anti-human Angptl4 antibodies against human Angptl4/FIAF and recombinant human Angptl4 fragment (standard) were obtained from R\&D systems USA, streptavidin-conjugated horseradish peroxidase (HRP), bovine serum albumin( BSA), tetramethyl-benzidine substrate system ( TMB) and $2 \mathrm{M} \mathrm{H}_{2} \mathrm{SO}_{4}$ were from Sigma-Aldrich company USA. All other chemicals were from Sigma.

Subjects: To examine the effect of plasma FFAs concentration on the levels of Angptl4 in human blood, plasma samples with known FFAs concentration were used. All samples that have been used in this study were human blood plasma of healthy male individuals who treated with a variety of physiological stimuli to enhance or reduce plasma fatty acid concentrations and had been stored at $-80^{\circ} \mathrm{C}$ for further analysis. The samples were divided into three experiments according to the type of treatment and conditions that have been used.

Experiment 1: In this experiment 48 plasma samples of nine healthy male volunteers (age: $24.4 \pm 1.3$ years, BMI: $22.2 \pm 0.8 \mathrm{~kg} /$ $\mathrm{m}^{2}$, fat-free mass $58.0 \pm 2.7 \mathrm{~kg}$ ) were tested. All samples have been taken from human subjects under three different conditions at two time points-t0 and after $3 \mathrm{~h}$ (t180). Three types of infusion have been used, Salbutamole ( $\beta_{1}$-adrenergic stimulation) and Dobutamine $\left(\beta_{2}\right.$ adrenergic stimulation), both were given to stimulate fat lipolysis and therefore, increase FFA levels in the blood. Also Salbutamol was combined with acipimox to block lipolysis and, thus decrease FFA levels in the blood. It is important to mention that plasma FFA concentrations were measured previously by another group [27-30] and we received the samples with known FFA concentrations.

Experiment 2: In this experiment 36 samples of nine healthy lean male subjects without a family history of diabetes mellitus, (age: $20 \pm$ 0.5 years, BMI: $21.7 \pm 0.6 \mathrm{~kg} / \mathrm{m}^{2}$, body fat $16.0 \pm 1.3 \%$ ) were analyzed. Samples have been taken from human subjects under two different conditions at two time points-t 0 and after $6 \mathrm{~h}(\mathrm{t} 360)$. In this study, two types of infusion have been used glycerol infusion as a control and caused low plasma FFAs and lipid infusion that increased plasma FFA levels. In addition, the concentration of plasma FFAs were already measured as previously mentioned $[28,30]$.
Experiment 3: 66 samples of twenty-two healthy, overweight male individuals (age: $34.8 \pm 1.3$ years, and body mass index: 28.8 $\pm 0.5 \mathrm{~kg} / \mathrm{m}^{2}$ ) were examined. Samples have been taken from human subjects under two different conditions at two time points-day 1 and after 25 days All the human subjects received weekly treatment with $80 \mathrm{mg}$ regulated human recombinant leptin [polyethylene glycerolOB Protein (PEG-OB)] or matching placebo for 25 days while their energy intake was reduced to $2.1 \mathrm{MJ} / \mathrm{d}$ by means of a very low energy diet (semi-starvation). In both treatments plasma FFAs concentration which were measured significantly elevated during the baseline and the end of treatment due to the effect of sever energy restriction conditions that enhance the lipolysis and release FFAs into the circulation $[29,30]$.

\section{Methods}

Sandwich Enzyme-Linked Immunoassay: In this study sandwich Enzyme-Linked Immunosorbent Assay (ELISA) was used for measurement of this protein in human plasma under the influence of various stimuli. According to Angptl4 ELISA Protocol, the antihuman Angptl4 monoclonal goats IgG antibody $(0.2 \mathrm{mg} / \mathrm{ml})$ was used for coating a 96-well microtiter plate and incubate the plate overnight at $4^{\circ} \mathrm{C}$. The absorbance at $450 \mathrm{~nm}$ was measured on a MultiSkan spectrophotometer.

\section{Statistical analysis}

Data are expressed as the mean \pm standard deviation. One wayANOVA (SPSS version 20.0) and LSD post hoc test were used to determine the mean differences between groups. Values are considered significantly different at the level of $<0.05$.

\section{Results}

As already mentioned before, the results of this project are presented in three parts based on the type of treatment that has been given to the human subjects which can be divided into three experiments as fellows.

\section{Experiment 1}

Effect of elevated and reduced plasma FFA concentrations through the stimulation of lipolysis by either Salbutamol (SAL) or Dobutamine (DOB) as well as with a blocker of lipolysis SAL plus acipimox (SAL+ACI) on plasma Angptl4 levels in healthy subjects were examined.

Raising FFAs upon SAL and DOB stimulation: As shown in Figure $1 \mathrm{~A}$, administration of SAL for $3 \mathrm{~h}$ (t180) significantly increased FFA concentrations up to $(470.6 \mu \mathrm{mol} / \mathrm{l})$ compared with the baseline t0 $(340.4 \mu \mathrm{mol} / \mathrm{l})$. Elevated plasma FFA upon SAL stimulation significantly increased plasma Angptl4 levels $(21.2 \pm 11.1)$ at t180 compared with $(15.8 \pm 10.7, \mathrm{P}<0.004)$ at $\mathrm{t} 0$.

While, the increase in plasma FFA was significantly higher in the DOB condition than in SAL condition $611.8 \mu \mathrm{mol} / \mathrm{l}$ at $\mathrm{t} 180$ compared with $443.7 \mu \mathrm{mol} / \mathrm{l}$ at $\mathrm{t} 0$. The higher FFA levels upon DOB also induced increases in the levels of plasma Angptl4 (21.5 \pm 10.0 vs.16.8 \pm 9.7 at t0, $\mathrm{P}<0.002$ ) (Figure 1B).

Lowering FFAs upon SAL+ACI infusion: As shown in Figure 1C, plasma FFA concentrations at the baseline (t0) and after $3 \mathrm{~h}(\mathrm{t} 180)$ were significantly lower after administration of acipimox than after either the DOB or SAL condition (67 and $134 \mu \mathrm{mol} / \mathrm{l}$, respectively). Lowering FFAs induced a significant decrease in the levels of plasma Angptl4 at t180 $(19.7 \pm 12.6)$ compared with $(22.3 \pm 12.96, \mathrm{P}<0.002)$ at $\mathrm{t} 0$.

\section{Experiment 2}

In this experiment the effect of elevated and reduced plasma FFA 
concentrations after infusion of either lipid or glycerol on plasma Angptl4 levels were analysed.

Lowering plasma FFAs upon glycerol infusion: In agreement with previous studies [28], it was shown that glycerol infusion during the baseline ( $\mathrm{t} 0)$ and the end of treatment after $6 \mathrm{~h}(\mathrm{t} 360)$ resulted in a marked decrease in plasma FFA concentrations in human subjects. In the present study, the lowering in plasma FFA in these samples were tested to further evaluate the effect of decreased plasma FFA on Angptl4 levels in human blood plasma and the resulting graph is shown in Figure 2A. The marked suppression in plasma FFA was accompanied by a decrease in Angptl4 plasma levels in 8 of 9 subjects and an increase in only one subject at $\mathrm{t} 360$ compared with the baseline plasma Angptl4 at t0. However, the degree of changes on plasma Angptl4 in response to suppression in plasma FFA levels was variant.

Raising plasma FFAs upon lipid infusion: As has been also shown by previous study that, lipid infusion during the baseline t 0 and the end of treatment after $6 \mathrm{~h}(\mathrm{t} 360)$ resulted in an increase in plasma FFA levels in human subjects [28]. Interestingly, in our study the rise in plasma FFA induced markedly increases in the plasma levels of Angptl4 in 4 of 9 healthy subjects at $\mathrm{t} 360$ compared with the baseline plasma Angptl 4 at $\mathrm{t} 0$, whereas three individuals showed slightly increase and two no change in the concentration of plasma Angptl4 as shown in Figure 2B. The variation in the levels of plasma Angptl4 upon changes in plasma FFA concentrations can be clearly observed in the Figure 2 . Since, some subjects show a marked increase in plasma Angptl4 but others have mild to moderate elevation. Furthermore, few subjects don't show any change in the level of plasma Angptl4 under the effect of alteration in plasma FFA levels.

\section{Experiment 3}

To evaluate further the effect of raising plasma FFA on plasma Angptl4 levels, plasma samples from 22 healthy, overweight male individuals during sever energy restriction (semi-starvation) on day 1 and after 25 days were tested.

\section{Raising plasma FFAs during semi-starvation}

In the previous study, they found that plasma concentrations of FFAs were increased during semi-starvation for 25 days in overweight male individuals compared with the concentrations of FFAs on day 1 [29]. In the present study, these samples were analysed to investigate the correlation between plasma Angptl4 concentrations and the levels of plasma FFA, the resulting graph is presented in Figure 3. Similar for previous results, the rise in plasma FFA resulted in an increase in plasma Angptl4 in 20 of 22 healthy, overweight subjects on day 25 compared with the baseline plasma Angptl4 on dayl. Whereas, two individuals showed a decrease or no change in the concentration of plasma Angptl4. The variability in the levels of plasma Angptl4 in response to the changes in plasma FFA concentrations in human subjects also can be observed clearly in Figure 3.

Taken together, these data indicate clearly that there is a positive proportion relationship between the plasma levels of Angptl4 and plasma FFA concentrations in human subjects and both most probably simulate or inhibit each other. Furthermore, it is interesting to note that the plasma levels of FFA might be involved in mediating the hyperlipidemic effect of Angptl4 in the circulation. In addition, the metabolic function of Angptl4 as a powerful regulator of lipid metabolism and stimulating adipose tissue lipolysis in healthy subjects that were fasted overnight was also supported by our finding.
(A)

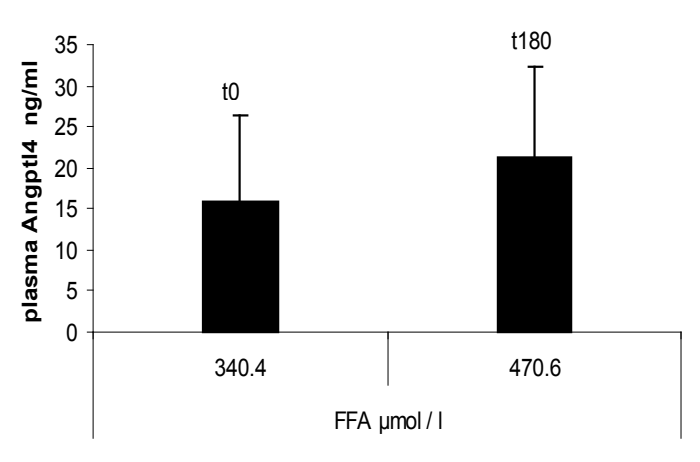

(B)

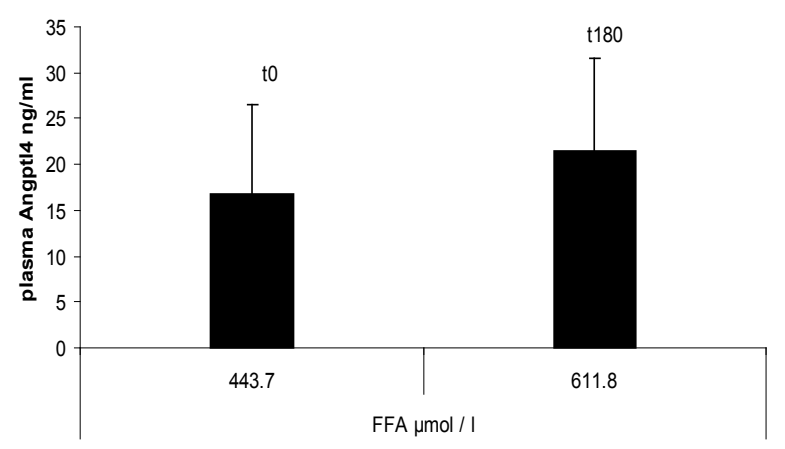

(C)

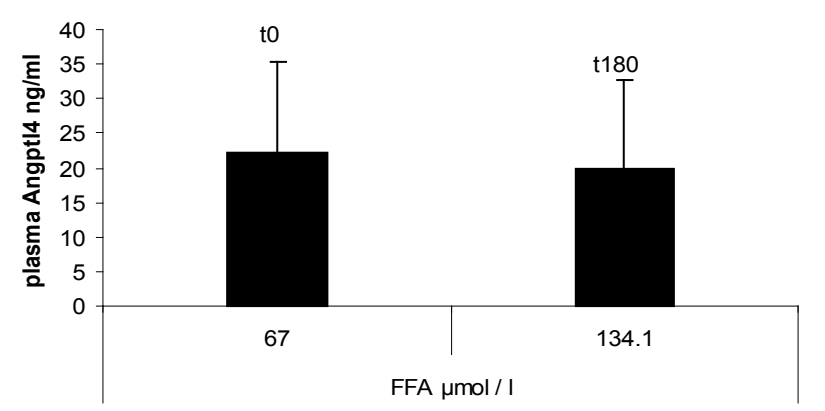

Figure 1: Effect of plasma levels of FFAs on Angptl4 levels in human blood plasma in 48 subjects on t0 and t180. A, Raising plasma FFAs upon SAL stimulation increased plasma Angptl4 levels. B, Raising plasma FFAs upon DOB stimulation increased plasma Angpt/4 levels. C, Lowering plasma FFAs upon SAL+ACI infusion decreased plasma Angptl4 levels. Values are means \pm SE. $P<0.004,<0.002,<0.002$, respectively. 


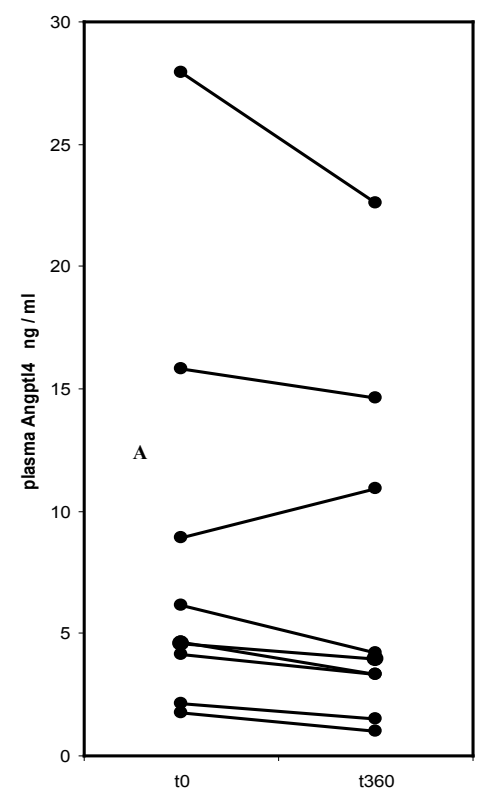

Time after glycerol infusion

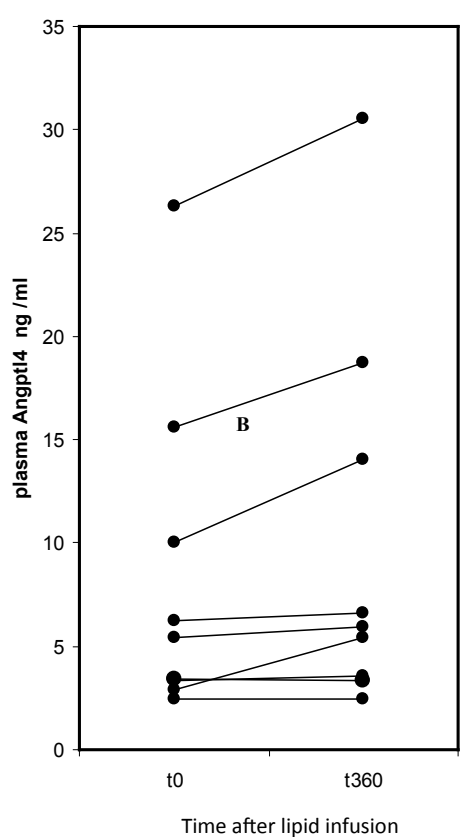

Figure 2: Plasma Angptl4 levels in response to changes in plasma FFA concentrations on t0 and t360 in 9 subjects. A) Lowering plasma FFA levels decreased Angptl4 plasma concentrations after glycerol infusion for $6 \mathrm{~h}$. B) Rise in plasma FFA levels increased Angptl4 plasma concentrations after lipid infusion for $6 \mathrm{~h}$. All measurements were in duplicate and averaged.

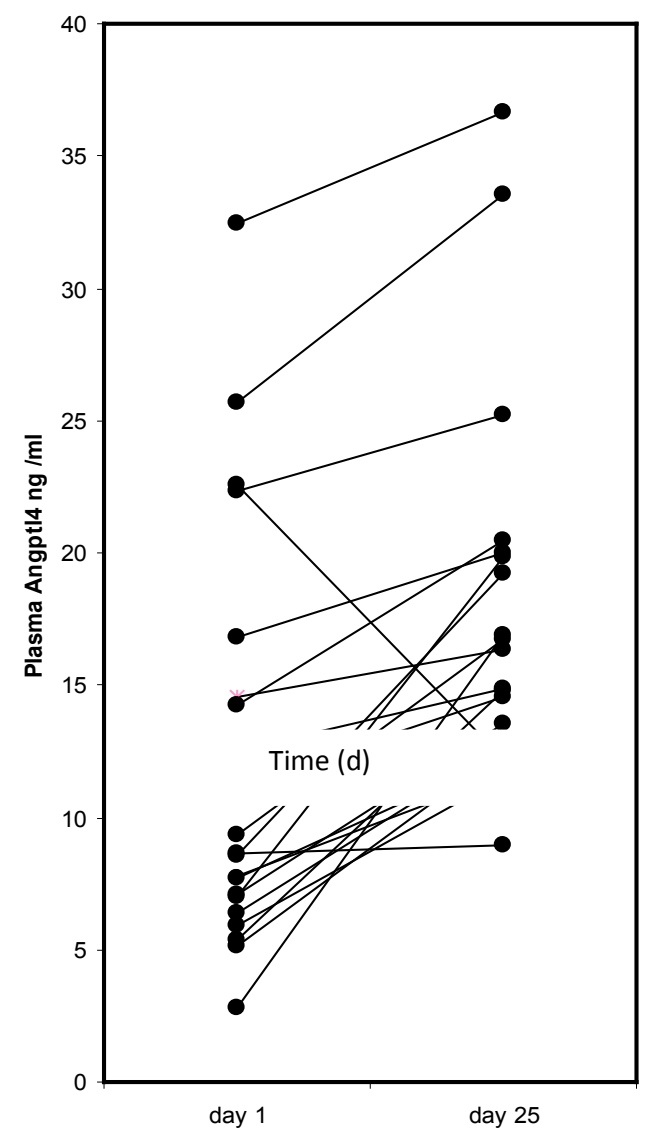

Figure 3: Quantification the effect of plasma FFA concentrations on Plasma Angptl4 levels on day 1 and after 25 days in 22 subjects. Rise in plasma FFA levels increased Angpt/4 plasma concentrations after sever energy restriction. All measurements were in replicate and averaged. 


\section{Discussion}

In the present study we have analyzed the effect of changes in plasma FFA levels on the concentration of Angptl4 in human plasma as characterized by ELISA method. It is clearly shown that the alterations in the levels of plasma FFA were associated with changes in the concentration of plasma Angptl4 in healthy subjects, suggesting that FFAs act as a potential regulator of Angptl4 expression and synthesis. The present study is the first study showing the correlation between the levels of plasma FFA and plasma Angptl4 upon low and high plasma FFA concentrations in humans. This result is in line with studies performed in mice, the effect of Angptl4 overexpression on plasma FFAs and having the same net effect. This finding further favors a role for fatty acids in the regulation of Angptl4 and suggests that the physiological function of Angptl4 is more likely related to fatty acid metabolism than to the regulation of energy metabolism.

From our study, plasma FFAs significantly rose in the healthy subjects upon both $\beta 1$-(salbutamol) and $\beta 1$-adrenergic stimulation (dobutamine) for $3 \mathrm{~h}$. The elevation of FFAs induced increases in the levels of plasma Angptl4 in all human subjects. Whereas, plasma FFA levels after administration of acipimox were significantly lower than during either dobutamine or salbutamol infusion [27,30], resulted in a decrease in the concentrations of Angptl4 also in all subjects. The changes in the levels of plasma Angptl4 in response to either stimulation or inhibition adipose tissue lipolysis reveals the role of Angptl4 in the regulation of FFA mobilization from adipose tissue. The increased levels of plasma Angptl4 in our study are in agreement with the acute elevation in plasma FFAs observed after injection of recombinant Angptl4 by others [17,31]. The major consequence of this action is diminished fat stores in fat cells and promotes fatty acid oxidative metabolism and uncoupling. On other hand, the levels of Angptl4 in plasma upon low or high plasma FFAs after glycerol and lipid infusion for $6 \mathrm{~h}$ as well as after semi-starvation for 25 days in healthy subjects surprisingly showed a large inter-individual variation.

Although all plasma samples were from healthy subjects and tested at the same time under the same conditions, indicating that the variation is not associated with body mass index or the age. One explanation is that Angptl4 might be associated with the variant of the human Angptl4 gene that encodes Angptl4 protein and the differences in the genetic basis of familial hyperlipidemia. Although, the molecular mechanisms of Angptl4 in humans are still unclear, and therefore further studies will be necessary to clarify this issue in humans [30].

Recently, it has become clear that Angptl4 is a downstream target gene of both PPAR $\alpha$ and PPAR $\gamma$, that is activated by fatty acids especially polysaturated fatty acids, as well as by various eicosanoids [18,3133]. The link between Angptl4 and the ligand-activated transcription factors that activate the transcription of genes involved in fatty acid metabolism, may explain the molecular mechanism of plasma Angptl4 regulation by either rising or lowering plasma FFAs. In addition, more recently $\mathrm{Ge}$ et al. [32] reported that adenovirus mediated expression of Angptl4 potently elevates plasma triglycerides and total cholesterol levels by inhibition of LPL and suppressing the clearance of VLDL from the circulation in mice. Blocking LPL is expected to result in a decrease plasma FFA levels, rather than an increase as observed by Yoshida et al. [31] whereas, our results suggest that elevated plasma Angptl4 is highly connected with an increase of plasma FFA levels. On the other hand, $\mathrm{Xu}$ et al. [18] reported that serum Angptl4 concentrations are low in patients with type 2 diabetes mellitus but not in obese individuals and there is no correlation between serum Angptl4 concentrations and serum levels of triglyceride and total cholesterol. However, it is known clinically that elevated FFA concentrations are associated with diabetes mellitus, obesity and hyperlipidemia [24].
In contrast, recently published paper by Stejskal et al. [34] reported that there were no differences between serum Angptl4 concentrations in patients suffering from diabetes mellitus and serum Angptl4 values from healthy individuals. Nevertheless, further studies, including investigation of the connection between human Angptl4 levels and circulating plasma lipid levels are necessary to better understand the role and the pathogenesis of Angptl4 in humans.

\section{Conclusion and Future Research}

In summary, the results of this study suggest that there is significant correlation between plasma Angptl4 concentrations and the levels of FFA. Moreover, we can conclude that plasma FFAs play a pivotal role in the regulation of Angptl4 expression and synthesis. Thereby, our results support the hypothesis that alteration in the plasma Angptl4 concentrations might be mediated by plasma FFA levels in human. Accordingly, based on the present study and the results from previous studies Angptl4 pharmacologically can represent interesting candidate for the therapeutic targeting of dyslipidemia. However, further studies are still needed to clarify the influence of an altered of plasma FFA and other lipid profiles on plasma Angptl4 protein and its gene in humans as well as determine the normal value of this protein in blood plasma in order to assess Angptl4 value as a new risk predictor and prognostic factor for the diagnosis of metabolic syndrome and its related disorders.

\section{Acknowledgment}

The authors are very grateful to the department of Nutrition and Dietetics, Faculty of Medicine and Health Sciences and RMC at UPM for their assistance in English editing and for allowing us to publish this manuscript. This study was supported by (Netherlands Fellowship Programme, Nuffic).

\section{Conflict of Interest}

The authors declare no competing interests to disclose.

\section{References}

1. Schoenhagen P, Nissen SE (2006) Identification of the metabolic syndrome and imaging of subclinical coronary artery disease: early markers of cardiovascular risk. J Cardiovasc Nurs 21: 291-297.

2. Ford ES, Giles WH, Mokdad AH (2004) Increasing prevalence of the metabolic syndrome among u.s. Adults. Diabetes Care 27: 2444-2449.

3. Oike Y, Yasunaga K, Suda T (2004) Angiopoietin-related/angiopoietin-like proteins regulate angiogenesis. Int J Hematol 80: 21-28.

4. Hato T, Tabata M, Oike $Y(2008)$ The role of angiopoietin-like proteins in angiogenesis and metabolism. Trends Cardiovasc Med 18: 6-14.

5. Kersten S (2005) Regulation of lipid metabolism via angiopoietin-like proteins Biochem Soc Trans 33: 1059-1062.

6. Kim I, Moon SO, Koh KN, Kim H, Uhm CS, et al. (1999) Molecular cloning expression, and characterization of angiopoietin-related protein. angiopoietinrelated protein induces endothelial cell sprouting. J Biol Chem 274: 26523 26528.

7. Oike Y, Yasunaga K, Ito Y, Matsumoto S, Maekawa H, et al. (2003) Angiopoietinrelated growth factor (AGF) promotes epidermal proliferation, remodeling, and regeneration. Proc Natl Acad Sci U S A 100: 9494-9499.

8. Koishi R, Ando $\mathrm{Y}$, Ono M, Shimamura M, Yasumo $\mathrm{H}$, et al. (2002) Angptl3 regulates lipid metabolism in mice. Nat Genet 30: 151-157.

9. Kersten S, Mandard S, Tan NS, Escher P, Metzger D, et al. (2000) Characterization of the fasting-induced adipose factor FIAF, a novel peroxisome proliferator-activated receptor target gene. J Biol Chem 275: 28488-28493.

10. Oike $Y$, Akao M, Kubota $Y$, Suda T (2005) Angiopoietin-like proteins: potential new targets for metabolic syndrome therapy. Trends Mol Med 11: 473-479.

11. Sukonina V, Lookene A, Olivecrona T, Olivecrona G (2006) Angiopoietin-like protein 4 converts lipoprotein lipase to inactive monomers and modulates lipase activity in adipose tissue. Proc Natl Acad Sci U S A 103: 17450-17455.

12. Li C (2006) Genetics and regulation of angiopoietin-like proteins 3 and 4. Curr Opin Lipidol 17: 152-156. 
Citation: Ali FHH, Ranneh Y (2013) Angiopoietin-like Protein 4 and the level of Free Fatty Acids in Human Blood Plasma: Is there a link? Med chem 3: 276-281. doi:10.4172/2161-0444.1000151

13. Conklin D, Gilbertson D, Taft DW, Maurer MF, Whitmore TE, et al. (1999) Identification of a mammalian angiopoietin-related protein expressed specifically in liver. Genomics 62: 477-482.

14. Cazes A, Galaup A, Chomel C, Bignon M, Brechot N, et al. (2006) Extracellular matrix-bound angiopoietin-like 4 inhibits endothelial cell adhesion, migration, and sprouting and alters actin cytoskeleton. Circ Res 99: 1207-1215.

15. Kim I, Kim HG, Kim H, Kim HH, Park SK, et al. (2000) Hepatic expression, synthesis and secretion of a novel fibrinogen/angiopoietin-related protein that prevents endothelial-cell apoptosis. Biochem J 346 Pt 3: 603-610.

16. Yoon JC, Chickering TW, Rosen ED, Dussault B, Qin Y, et al. (2000) Peroxisome proliferator-activated receptor gamma target gene encoding a novel angiopoietin-related protein associated with adipose differentiation. Mol Cell Biol 20: 5343-5349.

17. Mandard S, Zandbergen F, van Straten E, Wahli W, Kuipers F, et al. (2006) The fasting-induced adipose factor/angiopoietin-like protein 4 is physically associated with lipoproteins and governs plasma lipid levels and adiposity. $J$ Biol Chem 281: 934-944.

18. Xu A, Lam MC, Chan KW, Wang Y, Zhang J, et al. (2005) Angiopoietin-like protein 4 decreases blood glucose and improves glucose tolerance but induces hyperlipidemia and hepatic steatosis in mice. Proc Natl Acad Sci U S A 102: 6086-6091.

19. Le Jan S, Amy C, Cazes A, Monnot C, Lamande N, et al. (2003) Angiopoietinlike 4 is a proangiogenic factor produced during ischemia and in conventional renal cell carcinoma. Am J Pathol 162: 1521-1528.

20. Harmey JH, Dimitriadis E, Kay E, Redmond HP, Bouchier-Hayes D (1998) Regulation of macrophage production of vascular endothelial growth facto (VEGF) by hypoxia and transforming growth factor beta-1. Ann Surg Oncol 5: 271-278.

21. White JR, Harris RA, Lee SR, Craigon MH, Binley K, et al. (2004) Genetic amplification of the transcriptional response to hypoxia as a novel means of identifying regulators of angiogenesis. Genomics 83: 1-8.

22. Ge H, Cha JY, Gopal H, Harp C, Yu X, et al. (2005) Differential regulation and properties of angiopoietin-like proteins 3 and 4. J Lipid Res 46: 1484-1490.

23. Mandard S, Zandbergen F, Tan NS, Escher P, Patsouris D, et al. (2004) The direct peroxisome proliferator-activated receptor target fasting-induced adipose factor (FIAF/PGAR/ANGPTL4) is present in blood plasma as a truncated protein that is increased by fenofibrate treatment. J Biol Chem 279: 34411-34420.
24. van Loon LJ, Thomason-Hughes M, Constantin-Teodosiu D, Koopman R Greenhaff PL, et al. (2005) Inhibition of adipose tissue lipolysis increases intramuscular lipid and glycogen use in vivo in humans. Am J Physiol Endocrinol Metab 289: E482-493.

25. Koster A, Chao YB, Mosior M, Ford A, Gonzalez-DeWhitt PA, et al. (2005) Transgenic angiopoietin-like (angptl)4 overexpression and targeted disruption of angpt/4 and angpt|3: regulation of triglyceride metabolism. Endocrinology 146: 4943-4950.

26. Havel RJ (1997) Postprandial lipid metabolism: an overview. Proc Nutr Soc 56: 659-666.

27. Hoeks J, van Baak MA, Hesselink MK, Hul GB, Vidal H, et al. (2003) Effect of beta1- and beta2-adrenergic stimulation on energy expenditure, substrate oxidation, and UCP3 expression in humans. Am J Physiol Endocrinol Metab 285: E775-782.

28. Hoeks J, Hesselink MK, Russell AP, Mensink M, Saris WH, et al. (2006) Peroxisome proliferator-activated receptor-gamma coactivator-1 and insulin resistance: acute effect of fatty acids. Diabetologia 49: 2419-2426.

29. Hukshorn CJ, Menheere PP, Westerterp-Plantenga MS, Saris WH (2003) The effect of pegylated human recombinant leptin (PEG-OB) on neuroendocrine adaptations to semi-starvation in overweight men. Eur J Endocrinol 148: 649655.

30. Kersten S, Lichtenstein L, Steenbergen E, Mudde K, Hendriks HF, et al. (2009) Caloric restriction and exercise increase plasma ANGPTL4 levels in humans via elevated free fatty acids. Arterioscler Thromb Vasc Biol 29: 969-974.

31. Yoshida K, Shimizugawa T, Ono M, Furukawa H (2002) Angiopoietin-like protein 4 is a potent hyperlipidemia-inducing factor in mice and inhibitor of lipoprotein lipase. J Lipid Res 43: 1770-1772.

32. Ge H, Yang G, Yu X, Pourbahrami T, Li C (2004) Oligomerization statedependent hyperlipidemic effect of angiopoietin-like protein 4. J Lipid Res 45 : 2071-2079.

33. Desvergne B, Wahli W (1999) Peroxisome proliferator-activated receptors: nuclear control of metabolism. Endocr Rev 20: 649-688.

34. Stejskal D, Karpisek M, Reutova H, Humenanska V, Petzel M, et al. (2008) Angiopoietin-like protein 4: development, analytical characterization, and clinical testing of a new ELISA. Gen Physiol Biophys 27: 59-63. 